\title{
Pengaruh Model Pembelajaran Inquiry Terhadap Hasil Belajar Siswa Pada Materi Pencemaran Lingkungan di SMA Swasta PAB 8 Saentis
}

\author{
Baby Arlita Lubis*, Binari Manurung, Fauziyah Harahap \\ Program Studi Pendidikan Biologi, Program Pascasarjana, Universitas Negeri Medan, Jl. Willem Iskandar Pasar \\ V Medan Estate, Deli Serdang, Sumatera Utara, Indonesia \\ *E-email: babyarlitalubis@gmail.com
}

\begin{abstract}
This study aims to determine the effect of inquiry based learning modelon students'learning outcome of the environmental pollutiontopic at SMA Swasta PAB 8 Saentis. The research method used is quasi experimentwith sample as much as 3 classes, those are takenby using the technic of cluster random sampling.Guided inquiry based learning model is taught in class $\mathrm{X}_{2}$, modified free inquiry based learning modelis taughtin class $\mathrm{X}_{5}$, and traditional based learning model is taughtin class $\mathrm{X}_{3}$. The instrument is used in this study islearning outcome test in form multiple choice. The techniqueof data analysis used in this study isanalysis covariatbyusingthe program of SPSS 21.0 for Windows. The study result showed that there was effect ofinquiry based learning modelon students' learning outcome $(\mathrm{F}=6.58 ; \mathrm{P}=0.002)$. Students' learning outcome that were taught by guided inquiry based learning model(73.36 \pm 11.443$)$ was highestthanmodified free inquiry based learning model(67.27 \pm 12.050$)$ was higherthan traditional based learning model $(64.00 \pm 13.561)$.
\end{abstract}

Key Words: Guided Inquiry, Modified Free Inquiry, Traditional, Learning Outcome, Environmental Pollution.

\section{PENDAHULUAN}

Salah satu masalah yang dihadapi dunia pendidikan menurut Sanjaya (2011) adalah masalah lemahnya proses pembelajaran. Dalam pembelajaran, anak kurang didorong untuk mengembangkan kemampuan berpikir. Proses pembelajaran didalam kelas diarahkan kepada kemampuan anak untuk menghapal informasi, otak anak terus-menerus dibiasakan untuk mengingat dan menimbun berbagai informasi tanpa dituntut menghubungkannya dengan kehidupan sehari-hari.

Hasil penelitian Program for International Student Assessment (PISA) 2012 yang berfokus pada literasi Ilmu Pengetahuan Alam (IPA) mengukuhkan peserta didik Indonesia menempati posisi ke-64 dari 65 negara peserta dengan skor rata-rata 382 pada aspek kemampuan peserta didik dalam mengidentifikasi masalah dalam memahami fakta-fakta alam dan lingkungan serta menggunakannya untuk memahami fenomena dan perubahan pada lingkungan hidup (Kemdikbud, 2014).
Permasalahan yang sama juga ditemukan di SMA Swasta PAB 8 Saentis. Berdasarkan hasil observasi awal dan komunikasi langsung dengan guru bidang studi biologi diketahui bahwa siswa masih memiliki kemampuan berpikir kritis rendah yang ditunjukkan dengan minimnya aktivitas bertanya, menjawab, menanggapi dan mengemukakan pendapat, menalar, belum terbiasa menyelesaikan suatu masalah dengan baik, dan mencoba mengambil suatu kesimpulan masih sangat kurang dalam kegiatan pembelajaran di kelas.Hal ini berdampak pada pencapaian hasil belajar biologi banyak yang belum mencapai kriteria ketuntasan minimal (KKM) rata-rata yang ditetapkan sekolah yaitu 75. Berdasarkan data Daftar Kumpulan Nilai (DKN) Biologi siswa kelas X SMA Swasta PAB 8 Saentis TA 2011/2012 hingga TA 2013/2014 bahwa hasil belajar biologi siswa masih rendah dan belum mencapai KKM. Nilai rata-rata siswa 59. Sedangkan kriteria ketuntasan minimal adalah 75 .

Pembelajaran biologi merupakan suatu proses penemuan dan menekankan pada 
pemberian pengalaman belajar secara langsung. Materi biologi SMA khususnya di kelas $\mathrm{X}$ tentang pencemaran lingkungan merupakan salah satu materi yang berhubungan secara langsung dengan kehidupan sehari-sehari. Namun, pada praktiknya selama ini proses pembelajaran tentang pencemaran lingkungan yang dilakukan oleh guru di dalam kelas masih menggunakan variasi pembelajaran yang rendah yang umumnya masih berorientasi pada guru (teacher centered).

Model pembelajaran inquiry yang dibelajarkan dalam penelitian ini terdiri dari model pembelajaran inkuiri terbimbing (guided inquiry) dan inkuiri bebas termodifikasi (modified free inquiry). Pada modified free inquiry kegiatan pembelajaran sama dengan kegiatan pembelajaran pada guidedinquiry, yaitu mengidentifikasi masalah, merumuskan masalah, merumuskan hipotesis, mengumpulkan informasi dan data, melakukan eksperimen untuk mencari solusi permasalahan, sampai pada akhirnya siswa menyimpulkan dan mampu menginformasikan hasil eksperimen tersebut di dalam kelas. Perbedaannya adalah pada modified free inquiry kegiatan merumuskan masalah dan prosedur pemecahan masalah tersebut dilakukan olehsiswa.

\section{METODE PENELITIAN}

\subsection{Tempat dan Waktu Penelitian}

Penelitian ini dilakukan di SMA Swasta PAB 8 Saentis, yang beralamat di Jalan Kali Serayu PTPN II Perkebunan
Saentis Kabupaten Deli Serdang.Penelitian tersebut dilakukan pada bulan Pebruari sampai dengan Juni 2016.

\subsection{Populasi dan Sampel}

Populasi dalam penelitian ini adalah seluruh siswa kelas X SMA Swasta PAB 8 Saentis, pada semester genap tahun pelajaran 2015/2016 yang berjumlah 245 orang siswa yang terdiri dari enam kelas paralel.

Sampel yang digunakan dalam penelitian ini diambil sebanyak 3 kelas yang ditentukan secara acak dengan menggunakan teknik cluster random sampling. Pengacakan dilakukan dengan cara undian dari enam kelas tersebut, sehingga diperoleh kelas $\mathrm{X}_{2}$ sebagai kelas eksperimen pertama yang dibelajarkan dengan menggunakan modelpembelajaran inkuiri terbimbing (guided inquiry) dan $\mathrm{X}_{5}$ sebagai kelas eksperimen kedua yang dibelajarkan dengan modelpembelajaran inkuiri bebas termodifikasi (modified freeinquiry) dan $\mathrm{X}_{3}$ sebagai kelas kontrol yang dibelajarkan dengan pembelajaran tradisional.

\subsection{Desain Penelitian}

Penelitian ini menggunakan metode eksperimen semu (quasi experimental research), yang terdiri dari dua kelompok eksperimen (guided inquiry dan modified freeinquiry) dan satu kelompok kontrol (tradisional), dirancang dengan menggunakan pretest-posttest experiment and control group design. Desain penelitian tersaji pada tabel 1 berikut ini.

Tabel 1. Pretest-Posttest Experiment and Control Group Design

\begin{tabular}{cccc}
\hline Kelas & Pretest & Perlakuan & Postest \\
\hline $\mathrm{X}_{2}$ & $\mathrm{~T}_{1}$ & $\mathrm{Y}_{1}$ & $\mathrm{~T}_{1}$ \\
$\mathrm{X}_{5}$ & $\mathrm{~T}_{2}$ & $\mathrm{Y}_{2}$ & $\mathrm{~T}_{2}$ \\
$\mathrm{X}_{3}$ & $\mathrm{~T}_{3}$ & $\mathrm{Y}_{3}$ & $\mathrm{~T}_{3}$ \\
\hline
\end{tabular}

$\mathrm{Y}_{1} \quad$ : Perlakuan dengan menggunakan model pembelajaran guided inquiry

$\mathrm{Y}_{2}$ : Perlakuan dengan menggunakan model pembelajaran modified free inquiry

$\mathrm{Y}_{3} \quad$ : Perlakuan dengan menggunakan pembelajaran tradisional

$\mathrm{T}_{1} \quad$ : Hasil belajar biologi siswa

\subsection{Teknik Analisis Data}

\subsubsection{Teknik Analisis Deskriptif}

Teknik analisis deskriptif dimaksudkan untuk mendiskripsikan data hasil penelitian meliputi mean, median, modus, varians, standar deviasi, nilai minimum dan nilai maksimum data. Data tersebut selanjutnya disajikan dalam 
bentuk tabel distribusi frekuensi menggunakan aturan Sturges dan dalam bentuk histogram.

\subsubsection{Teknik Analisis Inferensial}

\subsubsection{Uji Prasyarat Normalitas Data}

Uji normalitas data dimaksudkan untuk menentukan normal tidaknya distribusi data penelitian, artinya apakah penyebarannya dalam populasi bersifat normal. Uji normalitas dilakukan dengan uji Kolmogorov-Smirnov. Data dinyatakan berdistribusi normal jika probabilitas atau nilai Sig $>0,05$.

Uji homogenitas data dimaksudkan untuk mengetahui perbedaan varians data, artinya apakah kelompok-kelompok yang membentuk sampel berasal dari populasi yang sama (penyebarannya dalam populasi bersifat homogen). Uji homogenitas data dilakukan dengan uji Levene's Test. Data dinyatakan homogen jika probabilitas atau nilai Sig $>0,05$.

\subsubsection{Uji Hipotesis}

Setelah persyaratan terpenuhi selanjutnya dilakukan pengujian hipotesis penelitian, untuk data dan hasil belajar dan kemampuan berpikir kritis siswa di analisis dengan menggunakan teknik analisis kovariat (anacova). Jika hasil analisis menggambarkan adanya pengaruh yang signifikan antara ketiga kelas perlakuan yang berbeda tersebut, maka dilakukan uji lanjut dengan uji Tukey's. Keseluruhan data penelitian dianalisis dengan menggunakan aplikasi SPSS 21.0 for windows.

\section{HASIL DAN PEMBAHASAN}

\subsection{HASIL}

\section{Pengaruh ModelPembelajaran Terhadap Hasil Belajar}

Hasil Anacova dengan menggunakan SPSS 21.0 menunjukkan bahwa model pembelajaran secara sangat signifikan berpengaruh terhadap hasil belajar siswa $(\mathrm{F}=6,58 ; \mathrm{P}=0,002)$ dan data pretes berkorelasi dengan data postes hasil belajar siswa $(\mathrm{F}=10,93 ; \mathrm{P}=0,001)$. Selanjutnya hasil uji Tukey menunjukkan bahwa hasil belajar siswa yang dibelajarkan dengan modelguided inquiry $73,36 \pm 11,44$ $(\bar{X} \pm S B)(\mathrm{P}=0,057)$, tidak berbeda secara signifikan dengan hasil belajar siswa yang dibelajarkan dengan modelmodified free inquiry67,27 $\pm 12,05(\bar{X} \pm S B) \quad(\mathrm{P}=0,057)$, dan berbeda secara sangat signifikandengan hasil belajar siswa yang dibelajarkan dengan pembelajaran tradisional $\quad 64,00 \pm 13,56 \quad(\bar{X} \pm S B)$ $(\mathrm{P}=0,001)$. Data tersebut dapat dilihat pada Gambar 4.1. berikut ini.

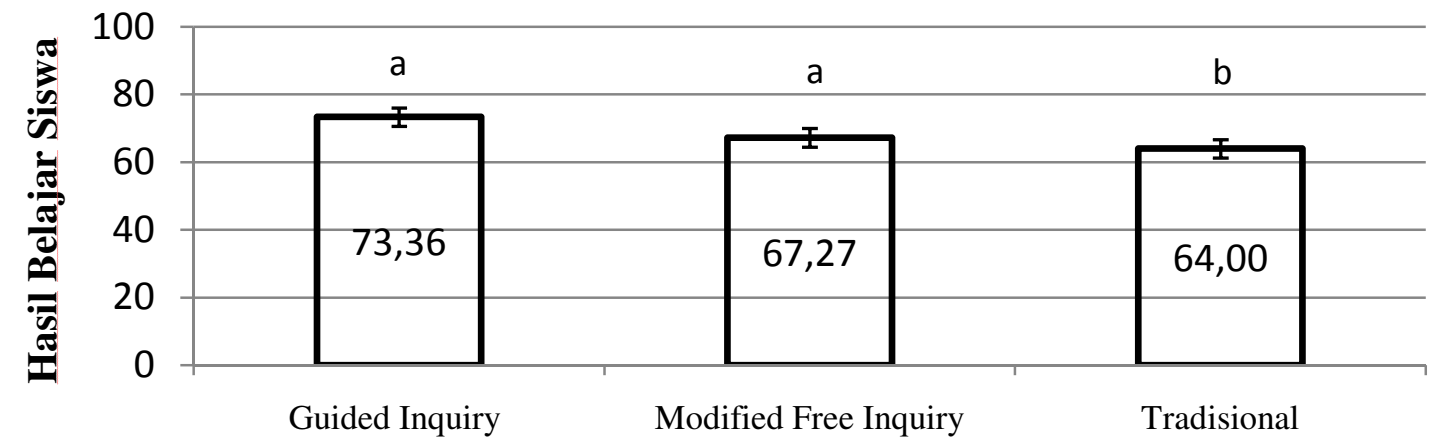

Keterangan:

- Huruf yang sama (a-a) berarti tidak berbeda secara signifikan

- Huruf yang berbeda (a-b) berarti berbeda secara signifikan

Gambar 1.Pengaruh Model Pembelajaran Terhadap Hasil Belajar Siswa Kelas X SMA Swasta PAB 8 Saentis $(\mathrm{P}=0,002<0,05)$

Berdasarkan rata-rata nilai hasil belajar siswa menunjukkan bahwa model pembelajaran guided inquiry memberikan pengaruh sebesar $8 \%$ lebih tinggi dibandingkan model pembelajaran modified free inquiry dan 16,32\% lebih tinggi dibandingkan pembelajaran tradisional. Model pembelajaran modified 
free inquiry memberikan pengaruh sebesar $7,12 \%$ lebih tinggi dibandingkan pembelajaran tradisional.

\subsection{PEMBAHASAN}

Pengaruh ModelPembelajaran Guided Inquiry, Modified Free Inquiry dan Pembelajaran TradisionalTerhadap Hasil Belajar Siswa

Berdasarkan hasil pengujian analisis kovariat diperoleh $(\mathrm{P}=0,002<0,05)$. Dengan demikian, $\mathrm{H}_{0}$ ditolak dan $\mathrm{H}_{\mathrm{a}}$ diterima, sehingga disimpulkan ada pengaruh yang sangat signifikan antara penggunaan model guided inquiry, modified free inquiry dan pembelajaran tradisional terhadap hasil belajar biologi siswa pada materi pencemaran lingkungan di SMA Swasta PAB 8 Saentis. Sesuai dengan hasil penelitian membuktikan bahwa model pembelajaran inkuiri sangat perlu diperhatikan, karena suatu materi pelajaran yang dibelajarkan dengan model pembelajaran tersebut sangat tepat untuk mencapai tujuan pembelajaran secara optimal dan maksimal sehingga hasil belajar siswa dapat meningkat dengan baik. Aunurrahman (2012) mengungkapkan bahwa penggunaan model pembelajaran yang tepat dapat memudahkan siswa untuk memahami pelajaran sehingga memungkinkan siswa mencapai hasil belajar yang baik. Hal ini sejalan dengan hasil penelitian oleh Seniwati (2015) yang menunjukkan bahwa terjadi peningkatan aktivitas dan hasil belajar biologi siswa melalui penerapan model pembelajaran inkuiri. Berdasarkan penelitian Siagian dan Maya (2012) yang dilaksanakan di Universitas Indraprasta PGRI, Fakultas Teknik, Matematika dan Ilmu Pengetahuan Alam pada November 2011-Januari 2012, menyatakan bahwa mahasiswa yang diajarkan dengan model pembelajaran inquiry memiliki hasil belajar yang lebih baik dibandingkan dengan mahasiswa yang diajarkan dengan model konvensional.

\section{DAFTAR RUJUKAN}

Amin, H., M. 2010. Hasil Belajar Biologi Ditinjau dari Pembelajaran Inkuiri dan Kemandirian Belajar pada Kelas VII SMP
Selanjutnya berdasarkan penelitian Tuan, Chin, Tsai, dan Cheng (2005) bahwa pembelajaran inkuiri secara signifikan dapat meningkatkan motivasi siswa terhadap pembelajaran sains dibandingkan dengan pembelajaran tradisional dan juga secara signifikan dapat meningkatkan motivasi siswa dengan gaya belajar yang berbeda terhadap pembelajaran sains. Model pembelajaran inkuiri direkomendasikan untuk meningkatkan prestasi belajar siswa. Menurut hasil penelitian oleh Amin (2010), menyimpulkan bahwa terdapat pengaruh pembelajaran dengan inkuiri terhadap hasil belajar biologi siswa, pengaruh kemandirian belajar terhadap hasil belajar biologi siswa, dan juga interaksi antara pembelajaran inkuiri dengan kemandirian belajar terhadap hasil belajar biologi ranah afektif dan psikomotor. Sejalan dengan pernyataan oleh Hanafiah dan Suhana (2009) menyatakan bahwa inquiry merupakan suatu rangkaian kegiatan pembelajaran yang melibatkan secara maksimal seluruh kemampuan peserta didik untuk mencari dan menyelidiki secara sistematis, kritis dan logis sehingga dapat menemukan sendiri pengetahuan, sikap dan keterampilan.

\section{KESIMPULAN}

Berdasarkan hasil penelitian dan pembahasan yang telah diuraikan pada bab sebelumnya, diperoleh kesimpulan sebagai berikut: Ada pengaruh pembelajaran yang sangat signifikan dari penggunaan model pembelajaran guided inquiry, modified free inquiry, dan tradisional terhadap hasil belajar biologi siswa pada materi pencemaran lingkungan di SMA Swasta PAB 8 Saentis. Hasil belajar biologi siswa yang dibelajarkan dengan model guided inquiry tidak berbeda secara signifikan dengan model modified free inquiry dan berbeda secara sangat signifikan dengan pembelajaran tradisional.

$N \quad 16$ Surakarta Tahun Pelajaran 2008/2009. Surakarta: Fakultas Keguruan dan Ilmu PendidikanUniversitas Sebelas Maret. 
Anam, K. 2015. Pembelajaran Berbasis Inkuiri. Yogyakarta: Pustaka Pelajar.

Arikunto, S. 2012. Dasar-Dasar Evaluasi Pendidikan Edisi 2. Jakarta: Bumi Aksara.

Ariyati, E. 2010. Pembelajaran Berbasis Praktikum Untuk Meningkatkan Kemampuan Berpikir Kritis Mahasiswa. Jurnal Matematika dan IPA. 1(2): 1-11.

Brickman, P., C. Gormally, N. Armstrong, B. Hallar. 2009. Effects of Inquiry-based Learning on Students' Science Literacy Skills and Confidence. International Journal for the Scholarship of Teaching and Learning. 3(2): 1-22.

Ennis, R. H. 1993. Critical Thinking Assessment. Theory Into Practice. 32(3): 179-186.

Ennis, R. H., W. L. Gardiner, R.. Morrow, P. Dieter, L. Ringel. 1964. The Cornell ClasReasoning Test, Form $X$. UrbanaChampaign: Illinois Critical Thinking Project, Department of Educational Policy Studies, University of Illinois.

Fisher, A. 2009. Berpikir Kritis: Sebuah Pengantar. Jakarta: Erlangga.

Gulo, W. 2008. Strategi Belajar Mengajar. Jakarta: Grasindo.

Hapsari, D. P., Suciati, S., dan Marjono. 2012. Pengaruh Model Inkuiri Terbimbing dengan Diagram $\mathrm{V}$ (Vee) dalam Pembelajaran Biologi terhadap Kemampuan Berpikir Kritis dan Hasil Belajar Siswa. Pendidikan Biologi. 4(3): 16-28.

Haryono. 2006. Model Pembelajaran Berbasis Peningkatan Keterampilan Proses Sains. Jurnal Pendidikan Dasar. 7(1): 1-13.

Kemdikbud. 2014. Buku Guru Ilmu Pengetahuan Alam SMP/MTs Kelas VII (Edisi

Kronberg, J. R. dan Griffin, M. S. 2000. Analysis Problem a Means to Develoving Students' Critical-Thinking Skills. Journal of College Science Teaching. March/April 2000. (1): 348-352.

Kuhlthau, C.C. 2010. Guided Inquiry: School Libraries in the 21st Century. School Libraries Worldwide. 16 (1): 17-28.

Nurochmah, T. 2008. Pengaruh Pendekatan Inkuiri terhadap Peningkatan Keterampilan Proses Sains Siswa dalam Proses Pembelajaran IPA Biologi pada Materi Pokok Sistem Pencernaan Makanan pada Manusia. Yogyakarta: Fakultas Sains dan Tekonologi Universitas Islam Negeri Sunan Kalijaga.
Ozgelen, S. 2012. Students Science Process Skills within a Cognitive Domain Framework.Journal of Mathematics Science and Technology Education 8(4): 283-292.

Paidi. 2007. Peningkatan Scientific Skill Siswa Melalui Implementasi Metode Guided Inquiry Pada Pembelajaran Biologi di SMAN 1 Sleman. Yogyakarta: FMIPA Universitas Negeri Yogyakarta.

Parr, B., dan M. C. Edwards. 2004. InquiryBased Instruction In Secondary Agricultural Education: Problem Solving An Old Friend Revisited. Journal of Agricultural Education. 45(4): 106-117.

Pratiwi, D. A., Maryati, S., Srikini, Suharno, S. Bambang. 2012. Biologi untuk SMA/MA Kelas X. Jakarta: Erlangga.

Quitadamo, I. J., C. L. Faiola, J. E. Johnson, and M. J. Kurtz. 2008. Community-based Inquiry Improves Critical Thinking in General Education Biology. CBE-Life Sciences Education. 7(3): 327-337.

Rahmatsyah dan Simamora, H. 2011. Pengaruh Keterampilan Proses Sainsmelalui Model Pembelajaran Inkuiri Terbimbing terhadap Hasil BelajarSiswa pada Materi Pokok Gerak di Kelas VII SMP. Jurnal Penelitian Inovasi Pendidikan Fisika, 3(2): 15-16.

Revisi). Jakarta: Kemdikbud.

Rusche, S. N dan Kendra, J. 2011. "You Have to Absorb Yourself in It": Using Inquiry and Reflection to Promote Student Learning and Self-knowledge. Teaching Sociology. 39(4): 338- 353.

Rustaman, N. 2003. Strategi Belajar Mengajar Biologi. Bandung: Jurusan Pendidikan Biologi FPMIPA UPI.

Rustaman, N. 2007. Keterampilan Proses Sains. Bogor: Ghalia Indonesia.

Semiawan, C. 1989. Pendekatan Keterampilan Proses: Bagaimana Mengaktifkan Siswa dalam Belajar. Jakarta: PT. Gramedia.

Seniwati. 2015. Peningkatan Aktivitas, Sikap dan HasilBelajar Biologi Melalui PenerapanModel Pembelajaran Inkuiri Pada SiswaKelas X-1 SMA Negeri 1 Bontonompo. Jurnal Nalar Pendidikan, 3(1): 317-321.

Siagian, R.E.F. dan Maya, N. 2012. Metode Pembelajaran Inquiry dan Pengaruhnya terhadap Hasil Belajar Matematika Ditinjau dari Kreativitas Belajar. Jurnal Formatif. 2(1): 35-44.

Sohibi, M., dan Siswanto, J. 2012. Pengaruh Pembelajaran Berbasis Masalah dan 
Inkuiri Terbimbing Terhadap Kemampuan Berpikir Kritis dan Kreatif Siswa. Semarang: Prodi Pendidikan Fisika IKIP PGRI.

Suciati, R. 2009. Belajar dan Pembelajaran 2. Jakarta: Universitas Terbuka.

Sudjana. 2002. Metode Statistika. Bandung: Tarsito.

Tuan, H. Chin, C., Tsai, C., Cheng, S. 2005. Investigating the Effectiveness of Inquiry Instruction on the Motivation of Different Learning Styles Students. International Journal of Science and Mathematics Education. 3(1): 541-566.
Wilson, D. C., Taylor, J. A., Kowalski, S. M., Carlson, J. 2010. The Relative Effects and Equity Inquiry-Based and Commonplace Science Teaching on Students' Knowledge, Reasoning, and Argumentation. Journal of Research in Science Teaching. 47(3): 276301.

Zion, M. 2007. Implementation Model of a Free Inquiry Curiculum. Science Education International. 18(2): 93-112.

Zion, M. and Irit, S. 2012. Which Type of Inquiry Project Do High School Biology Students Prefer: Free or Guided? Journal ofResearch Science Education. 42(2): 831848. 